\title{
Alienação da sexualidade, emancipação feminina e emancipação humana
}

\section{Alienation of sexuality, women's emancipation and human emancipation}

\author{
Samara Almeida Chaves Braga* \\ Susana Jimenez* \\ Jackline Rabelo*** \\ Ruth de Paula Gonçalves ${ }^{* * *}$ \\ Maria das Dores Mendes Segundo*****
}

\begin{abstract}
Resumo: Tomando por base a ontologia marxiana, o artigo enfoca a alienação da sexualidade em conexão com o trabalho alienado. Por esse prisma, apresenta elementos críticos quanto à retórica dominante acerca da emancipação feminina, ilustrada na histórica Declaração de Pequim. O estudo, de natureza bibliográfica e documental, reitera que a independência econômica da mulher - ainda que esta fosse efetivamente alcançada - não seria suficiente para garantir a emancipação feminina, como postulam, em larga medida, os organismos internacionais. Concluise, a partir de Marx; Lukács; e Mészáros; recorrendo, ainda, a Holanda (2005), que a emancipação feminina vincula-se organicamente à emancipação humana e, nesse escopo, deve efetivar-se a luta contra a específica opressão de gênero.
\end{abstract}

Palavras-chave: Ontologia marxiana. Emancipação feminina. Emancipação humana.

\begin{abstract}
On the basis of Marxian ontology, the article focuses on the alienation of sexuality, in connection with alienated work. From this point of view, it presents critical elements about the dominant rhetoric about female emancipation, illustrated by the historic Beijing Declaration (1995). The study, of a bibliographic and documentary nature, confirms that economic independence of women - even though this might be effectively achieved - would not be enough to ensure female emancipation, against the postulates enunciated to a large extent, the international organisms. It is concluded, from the standpoint of Marx; Lukács; Mészáros; and yet, Holanda, that
\end{abstract}

\footnotetext{
"Doutoranda em Educação pela Universidade Federal do Ceará (UFC). Professora de História da Escola de Ensino Médio José Bezerra de Menezes. Pesquisadora do Instituto de Estudos e Pesquisas do Movimento Operário (IMO/UECE). E-mail: samachaves5@hotmail.com

" Doutora em Educação pela United States International University (Estados Unidos), com pós-doutorado pela UNICAMP. Professora do Programa de Pós-Graduação em Educação da UFC. Diretora Emérita do IMO/UECE. E-mail: susana_jimenez@uol.com.br

*** Doutora em Educação pela UFC, com pós-doutorado pela École des Hautes Études en Sciences Sociales (EHESS), Paris, França. Professora da UFC. Pesquisadora do IMO/UECE. E-mail: jacklinerabelo@uol.com.br

..** Doutora em Educação pela UFC, com pós-doutorado pela Universidade Federal do Rio Grande do Norte (UFRN). Professora da Universidade Estadual do Ceará (UECE). Pesquisadora do IMO/UECE. E-mail: ruthm@secrel.com.br

***** Doutora em Educação pela UFC. Professora da UECE. Coordenadora do Mestrado Acadêmico Intercampi em Educação e Ensino (MAIE/UECE). Professora do Programa de Pós-Graduação em Educação (PPGE/UECE). Pesquisadora do IMO/UECE. E-mail: mendesegundo@uol.com.br
} 
female emancipation is organically connected to human emancipation, and in that scope the struggle against the specific gender oppression should be conducted.

Keywords: Marxian ontology. Women's emancipation. Human emancipation.

Recebido em: 11/11/2011. Aceito em: 20/11/2012.

\section{Introdução}

O presente artigo articula-se a um projeto investigativo acerca do complexo da alienação, na perspectiva da ontologia marxiana, destacando, por excelência, as formas de expressão do referido fenômeno no quadro do capitalismo contemporâneo.

No texto em foco, tratamos, com maior especificidade, do problema da alienação sexual, ou subalternidade sexual da mulher, no dizer de Lukács, organizando-se este, em duas partes.

$\mathrm{Na}$ primeira, revisamos, em linhas muito gerais, os elementos concernentes à centralidade ontológica do trabalho na reprodução do ser social, com todos os desdobramentos que tal pressuposto acarreta no plano das relações entre ser e consciência, indivíduo e gênero, em última análise, permitindo-nos apontar ao mesmo tempo, a essência histórica do homem e o homem como sujeito da história, em sua gênese, evolução e devir. Assinalamos, outrossim, o duplo caráter do trabalho, distinguindo o trabalho concreto, criador de valores de uso, portanto, um complexo de caráter universal, permanentemente necessário à reprodução do mundo dos homens; e a forma histórica assumida pelo trabalho na sociedade regida pelo capital, o trabalho abstrato, explorado.

O trabalho abstrato é, então, tomado como base para o entendimento do trabalho alienado, fundamento genético das múltiplas e complexas formas de manifestação da alienação na práxis social.

Entretanto, se, por um lado, assumimos, a partir de Marx, a gênese da alienação no trabalho abstrato donde tal fenômeno alcança o conjunto das práxis sociais, com severos impedimentos ao desenvolvimento dos indivíduos, enfatizamos, por outro lado, a possibilidade da superação desse complexo histórico em direção à emancipação humana, para além da sociabilidade fundada na subsunção do trabalho ao capital ${ }^{1}$.

Precisamente por esse prisma, particularizamos a problemática da alienação relativa à sexualidade, aliada à questão da subalternidade feminina, na tentativa de apreender de forma devidamente abrangente, o fundamento das relações entre os indivíduos na sociabilidade de classes. Com efeito, conforme Marx (2008), por meio das relações entre homens e mulheres, é possível avaliarmos em que medida a humanidade do ser social de fato naturalizou-se no mundo dos homens. Em termos afins, postula Lukács (1981) que, justamente na relação entre homem e mulher está representado o nível de desenvolvimento de uma dada forma de sociabilidade, uma vez que tal relação consigna, por excelência, a relação entre os indivíduos. Destacamos, ademais, que, segundo Lukács (1981) e, antes deste, Marx (2008), a sensibilidade e o ter são duas categorias que acompanham diretamente o processo de alienação da sexualidade. Por conseguinte, estas dimensões serão, ao longo do texto, oportunamente mencionadas.

Delimitados nossos pressupostos teóricos e, ainda, ressaltando, com o aporte de Mészáros (2003), a natureza da crise contemporânea do capital, seguimos para o segundo momento da exposição, debruçando-nos sobre a retórica vigente que cerca a problemática da emancipa-

\footnotetext{
1 Vale estabelecer, com Mészáros (2009), o processo de alienação, mormente, a possibilidade de sua superação, como de fundamental relevância para o esclarecimento de toda a obra marxiana. Na verdade, pontua o autor, que: "do problema da transcendência - nos Manuscritos de 1844 - como a negação e supressão da 'auto-alienação do trabalho', nasceu o sistema de Marx" (p. 23-4).
} 
ção da mulher, internacionalmente propagada sob a referência da Organização das Nações Unidas (ONU). Nesse sentido, destacamos elementos fundamentais da Declaração de Pequim, resultante da IV Conferência Mundial sobre as Mulheres, de 1995, aquele importante evento capitaneado pela ONU, por ocasião do jubileu de ouro da referida Organização e que se sucedeu a uma série de encontros promovidos, no plano internacional, em torno da problemática das mulheres desde, mais precisamente, a década de 1970, dentre as quais, contam-se as conferências do México e de Nairobi, realizadas, respectivamente, em 1975 e em 1985. É oportuno lembrar, com efeito, que a Carta das Nações Unidas, assinada em 1945, já trazia em seu teor, a institucionalização da igualdade de gênero como um direito fundamental e, desde então, havemos que reconhecer, a ONU vem se reportando à condição da mulher através de um conjunto diversificado de instrumentos, chegando a eleger 1975, o ano internacional da mulher. De fato, (através da promoção de conferências internacionais, ao lado da criação de uma comissão específica para cuidar dos direitos das mulheres, a Comission on the Status of Women (CWS), como registra Guarnieri (2010), "a ONU retirou as questões de gênero, em definitivo, do âmbito doméstico do Estado, trazendo-as para a realidade internacional, tornando-as, com isso, preocupações internacionais" (p. 25).

Todavia, com base nos pressupostos que nos guiam, sobrelevamos, ao fim e ao cabo, a impossibilidade da realização prática da agenda da ONU, mormente, no que toca aos itens essenciais contidos na Declaração de Pequim, no chão histórico da sociabilidade de classes fundamentada na lógica da subsunção do trabalho ao capital, agravada, ainda mais, nas condições da crise atual.

\section{Marx, Lukács e a Alienação da Sexualidade}

O filósofo húngaro, Gyorgy Lukács dedicou os longos anos de sua maturidade à recuperação ontológica do marxismo $\mathrm{Na}$ avaliação de Tertulian (1996), um dos grandes estudiosos da obra do referido filósofo, a Ontologia do Ser Social, de Lukács, representaria "a mais ambiciosa e a mais importante reconstrução filosófica do pensamento de Marx nos últimos decênios [...]" (p.
61), tendo resgatado o legado marxiano de duas deformações fundamentais: "(1) o determinismo economicista que anula a eficácia dos demais complexos da vida social e (2) a interpretação teleológica - dogmática - que considera toda ação histórica, um passo no caminho da realização de um fim imanente ou transcendente" (p. 60).

Ao empreender o resgate ontológico do marxismo, Lukács elucida que o homem como ser social, em sua gênese e desenvolvimento, ocupa o cerne do pensamento de Marx. Para Lukács, Marx teria, pois, estipulado a essência onto-histórica do homem, fundada no trabalho, pelo qual, o homem transforma o meio natural, cria o novo e se cria como um ser radicalmente novo.

Em outras palavras, Marx situa a origem da existência propriamente humana no trabaIho, compreendido como o ato que transforma a realidade objetiva, transformando, ao mesmo tempo, o próprio homem

Assim é que reafirma, em O Capital, que, através do trabalho, a espécie humana, pela determinação de sua atividade vital, consciente e ativa, se liberta dos estreitos limites da reprodução cega vigente no ser natural, saltando, por isso, para uma nova forma de ser, radicalmente distinta das esferas ontológicas que o precederam: o ser social. Para deixarmos a questão suficientemente explicitada, vale a pena recuperarmos a já clássica formulação de Marx (1988) sobre o papel e a dinâmica do trabalho na constituição do homem:

Antes de tudo, o trabalho é um processo de que participam o homem e a natureza, processo em que o ser humano com sua própria ação, impulsiona, regula e controla seu intercambio material com a natureza. Defronta-se com a natureza como uma de suas forças. Põe em movimento as forças naturais de seu corpo, braços e pernas, cabeças e mãos, a fim de apropriar-se dos recursos na natureza, imprimindo-lhes forma útil à vida humana. Atuando assim sobre a natureza externa e modificando-a, ao mesmo tempo modifica sua própria natureza. Desenvolve as potencialidades nela adormecidas e submete ao seu domínio o jogo das forças naturais (p. 202).

$\mathrm{Na}$ esteira do pensamento marxiano, Lukács reitera como tese central da sua Ontologia do Ser Social, o processo de trabalho, 
como modelo da práxis, protoforma da atividade propriamente humana. Recuperando as três esferas ontológicas que compõem o cosmo inorgânica, orgânica e social - Lukács assevera que o trabalho traz à luz uma nova qualidade de ser, capaz de ação consciente e livre, com todas as heterogêneas e contraditórias consequências que instituem a evolução histórica dos homens.

Assim é que, num movimento complexamente mediado, surge, em função das necessidades geradas no contexto das relações de produção dos meios de subsistência, a sociabilidade de classes e, com ela, a propriedade privada atrelada ao trabalho alienado. Desde o advento do trabalho alienado e da propriedade privada, vele lembrar, a produção da base material que garante a reprodução da sociedade vem se efetivando a partir de diferentes modos de dominação do homem pelo homem, prevalecendo, a partir da revolução burguesa, o trabalho assalariado.

Por isso, o nosso autor destaca que a essência da propriedade privada e sua relação com os indivíduos está atrelada à formação da sociabilidade de classes em um dado contexto histórico. Desse modo, de forma alguma, o complexo da alienação se configura em mediação inerente à natureza humana, embora devamos ressaltar que os níveis de degradação da essência humana são intensificados com o desenvolvimento do sistema capitalista.

Um ponto que merece a devida atenção é o fato de que a problemática da alienação fazse presente na totalidade da obra de Marx, aí, incluindo-se, obviamente, O Capital, conforme assevera Lukács (1981).

Não obstante, não podemos deixar de reiterar a relevância dos Manuscritos econômicofilosóficos (1844), conhecidos também como Manuscritos de Paris, para o entendimento radical da teoria marxiana da alienação. Como postula Mészáros (2009), "os Manuscritos de 1844 anteciparam adequadamente o Marx posterior, apresentando numa unidade sintética a problemática de uma reavaliação ampla, centrada na práxis, de todas as facetas da experiência humana" (p. 24, grifos no original).

Como bem sabemos, na obra supracitada, Marx analisa, o complexo da alienação, passando pelas dimensões do trabalho alienado que privilegia a criatura em detrimento do criador, contribuindo para o processo de mortificação dos indivíduos; identificando, assim, o estranhamento do trabalhador em relação ao produto do seu trabalho, ao processo de produção, ao gênero humano e aos outros homens. Daí, leva-nos a depreender que todo esse processo socialmente construído vai redundar na alienação do indivíduo em relação a ele próprio.

É oportuno sublinharmos que o trabaIhador, numa condição de alienação, torna-se prisioneiro do próprio objeto produzido por ele. O trabalho alienado permite que a vida produtiva dos trabalhadores apareça apenas como meio de satisfação das necessidades voltadas e limitadas à questão da sobrevivência, ou seja, um meio de manter a existência física dos trabalhadores, praticamente tolhendo seu desenvolvimento espiritual. Sob essa condição, os indivíduos não se reconhecem como membros partícipes do gênero humano. Nessa dinâmica, contudo, não perdem sua qualidade ontológica de seres genéricos.

Nesse sentido, explicita rigorosamente Marx (2008):

O animal é imediatamente um com a sua atividade vital. Não se distingue dela. É ela. O homem faz da sua atividade vital mesma um objeto da sua vontade e da sua consciência. Ele tem atividade vital consciente. Esta não é uma determinidade (Bestimmtheit) com a qual coincide imediatamente. A atividade vital consciente distingue o homem da atividade vital animal. Justamente, [e] só por isso, ele é um ser genérico (p. 84, grifos no original).

Ao mesmo tempo, conforme Marx (2008), o trabalho alienado faz do ser genérico "do homem, tanto da natureza quanto da faculdade genérica espiritual dele, um ser estranho a ele, um meio de sua existência individual. Estranha do homem o seu próprio corpo, assim como a natureza fora dele, tal como sua essência espiritual, sua essência humana" ( $p$. 85 , grifos no original).

Marx (2008) analisa, assim, as relações entre os indivíduos no seio da lógica da problemática da alienação, demonstrando, com insuperável clareza, que a realização do trabalho alienado na sociabilidade de classes torna-se um impedimento ao desenvolvimento genuíno das relações humanas: 
[...] uma conseqüência imediata disto, de o homem estar estranhado do produto do seu trabalho, de sua atividade vital e seu ser genérico é o estranhamento do homem pelo [próprio] homem. Quando o homem está frente a si mesmo, defronta-se com ele o outro homem. O que é produto da relação do homem com o seu trabalho, produto de seu trabalho e consigo mesmo, vale como relação do homem como outro homem, como o trabalho e o objeto do trabalho de outro homem (MARX, 2008, p. 85-6, grifos no original).

A imposição da limitação ao desenvolvimento da vida genérica dos indivíduos pela sociabilidade alienada da reprodução do capital representa a própria alienação da vida humana entre os indivíduos. Isto é, a carência de sentidos produz subjetividades também carentes de sentidos e fundamentadas pela lógica do ter em detrimento do ser. Não é descabido enfatizar, contudo, que Marx entende os limites engendrados pela sociedade de classes à plena relação entre o indivíduo e o gênero humano jamais como algo inerente à natureza humana, mas como elementos contraditórios de caráter histórico Desse modo entende a alienação como um processo possível de ser superado.

Nessa direção, Marx (2008) faz questão de esclarecer minuciosamente o processo de alienação existente na relação entre os homens na sociabilidade de classes, que se manifesta na relação com ele próprio e com os outros homens:

a relação do homem consigo mesmo the é primeiramente objetiva, efetiva, pela sua relação com o outro homem. Se ele se relaciona, portanto, com o produto do seu trabalho objetivado, enquanto objeto estranho, hostil, poderoso, independente dele, então se relaciona com ele de forma tal que um outro homem estranho (fremd) a ele, inimigo, poderoso, independente dele, é o senhor deste objeto ( $p$. 86-7, grifos no original).

É preciso ressaltar que a propriedade privada é consequência necessária para o florescimento do trabalho alienado. Somente com a compreensão da relação entre essas duas categorias históricas poderemos apontar perspectivas para a emancipação humana universal, pois presenciamos que, nessa relação, a alienação "está aí encerrada porque a opressão humana inteira está envolvida na relação do trabalhador com a produção, e todas as relações de servidão são apenas modificações e conseqüências dessa relação" (MARX, 2008, p. 89).

Em Marx, em suma, a denúncia à degradação das personalidades dos indivíduos proveniente das mais diversas formas de alienação na sociabilidade de classes atravessa a totalidade de sua obra, merecendo acento sobretudo, a passagem de seus Manuscritos de 1844, quando, ao reportar-se ao trabalho alienado, o autor qualifica de bestial o nível de incivilização dos indivíduos. O que Marx quer expressar, nessa linha valorativa, é que, vivendo sob a exploração peculiar à sociabilidade de classes, o indivíduo está alienado a um processo de sensibilização similar às funções dos animais, encontrando-se, por isso, impossibilitado de tornar-se plenamente homem do homem.

Lukács (1981) recupera, na obra marxiana, as bases ontológicas da problemática da alienação, relevando, sobremaneira, o nível de sensibilidade que é manifestado nas relações entre homens e mulheres.

Denomina a alienação constituinte das relações entre homens e mulheres de alienação da sexualidade ou subalternidade sexual da mulher, advogando que, no processo de sensibilização dos sentidos humanos, no processo de o homem tornar-se ser social, a relação entre o homem e a mulher abaliza, de maneira explícita, o nível de alienação de uma determinada sociabilidade.

Assevera, ademais, que são diversas as formas de alienação responsáveis pela legitimação e estruturação da alienação econômica em torno da categoria do ter, no entanto, a degradação dos efeitos desse processo nas personalidades dos indivíduos é particularmente evidenciada na alienação da vida sexual.

Vale assinalar que, na estruturação da alienação econômica, operam mediações intrínsecas a esse processo, por exemplo: a alienação provocada por mecanismos ideológicos, a alienação do homem em relação à mulher e da mulher em relação ao homem, a alienação das relações cotidianas que limitam os indivíduos à condição do ser em-si, a alienação religiosa; dentre outras. Não podemos tratar essa problemática como fenômeno geral e abstrato, tendo em vista que só é possível chegar aos seus fundamentos ontológicos, entendendo as mediações contraditórias 
e dialéticas que os envolvem. De todo modo, para ambos, Marx e Lukács, especificamente na alienação da vida sexual, tornam-se mais transparentes os níveis dos sentidos humanos mediados pela categoria do ter.

Dito de outro modo, na relação do homem com outro homem, encontramos a relação genérico-natural do homem com a mulher. Nesse sentido, Lukács (1981) põe em destaque a citação de Marx nos Manuscritos de Paris sobre a posição de Ferkuson em relação à alienação da vida sexual entre os indivíduos, assinalando que, através dessa relação, podemos avaliar o grau de civilidade que o homem conseguiu atingir num ponto determinado de sua evolução histórico-social.

Como destaca Holanda (2005), com efeito, para Marx:

a relação do homem com a mulher é a mais natural relação do homem com o homem. Nela se mostra, pois, até que ponto o comportamento natural do homem tornouse humano". [Pode-se também avaliar nesta relação] "até que ponto a necessidade do homem tornou-se necessidade humana; até que ponto, pois, o outro homem como homem tornou-se uma necessidade para o homem, e até que ponto o homem, na sua existência a mais individual, é por um tempo ente de comunidade" (p. 55, grifos da autora).

Em outras palavras, na relação mais natural do homem com outro homem, fica aclarado até que ponto esse outro homem tornou-se uma necessidade ao desenvolvimento da essência autêntica do homem em essência natural. É preciso ter em mente, contudo, que, não obstante numa sociabilidade alienada, a essência humana encontre-se praticamente reduzida à natureza das necessidades animais, esta essência, ainda que alienada e manipulada, jamais poderá retroagir na escala ontológica ao nível do ser animal.

Explicita Lukács (1981), ademais, que a sensibilidade, em sua específica legalidade, representa, em primeiro lugar, o salto ontológico do ser social em relação ao ser orgânico e, em segundo lugar, a possibilidade da transformação da personalidade particular em personalidade não-mais-particular dos indivíduos. Tal transformação configuraria, em verdade, um segundo salto ontológico, viabilizando a que os indivíduos gozem de oportunidades iguais e plenas de desenvolver suas mais genuínas capacidades. Todavia, os sentidos dos entes sociais emaranhados nas relações de produção engendradas pelo trabalho subsumido ao capital incriminam-se, a ferro e fogo, na vida cotidiana, onde vai impregnar-se à sexualidade (alienada).

Uma mediação importante entre a sensibilidade e a alienação da vida sexual mencionada por Lukács (1981) é a categoria do ter, que alicerça, inexoravelmente, a relação de desumanização do trabalho submetido ao capital. Conforme o autor (1981), ademais, a sensibilidade dos indivíduos forjada na lógica da reprodução capital-trabalho se reduziria, a rigor, ao mais exacerbado individualismo, o qual estaria suficientemente representado na priorização do ter em detrimento da igualdade de oportunidades ao desenvolvimento das capacidades humanas, negado aos trabalhadores.

Na verdade, nosso filósofo húngaro enfatiza continuamente a relevância de superarmos o homem alienado dos seus sentidos enraizados no complexo do ter com todas as mediações peculiares ao processo de reprodução social fundada na relação capital-trabalho. Assim, citando Marx, explica: "a objetivação da essência humana, tanto do ponto de vista teórico como prático, é necessária para humanizar os sentidos do homem e criar a sensibilidade humana correspondente a toda riqueza do ser humano natural" (LUKÁCS, 1981, p. 44). A sensibilidade do indivíduo como homem do homem, como o autor é consistente em anotar, só poderá efetivarse mediante a plena humanização das relações entre os sexos ${ }^{2}$.

Ou seja, na concepção marxianolukácsiana, os sentidos humanos só poderão se desenvolver plenamente em direção a uma generidade para-si, com a abolição da categoria do ter que permeia a subsunção do valor-de-uso

\footnotetext{
${ }^{2}$ Lukács (1981) registra, a partir da obra A Origem da Família e da Propriedade, que, após o declínio das formas de vida no matriarcado, o domínio do homem e a opressão da mulher passaram a constituir o durável fundamento da convivência social entre os seres humanos na sociabilidade de classes, recuperando, ainda, com Engels, que "A reviravolta do matriarcado significou a derrota no plano universal do sexo feminino. O homem toma nas mãos até a direção da casa, a mulher foi aviltada, dominada, tornada escrava de seus desejos e simples instrumento para produzir fiIhos" (p. 23).
} 
ao valor-de-troca. Nesta relação, os processos de reificação dos indivíduos e de fetichização das mercadorias são manifestados, precisamente, pelo ter em detrimento do ser. Para Marx (2008) e Lukács (1981), outrossim, a emancipação humana em relação ao ter com todos os seus desdobramentos só poderá efetivar-se com o fim da alienação da vida sexual entre os indivíduos, entre os homens e as mulheres, entre os homens e os outros homens. Nessa perspectiva, não podemos deixar de assumir que a luta pela emancipação feminina é uma luta relevante como um meio em favor da emancipação humana.

Estudiosa da problemática da alienação em Lukács, Holanda (2005) demonstra bem compreender tal postulado, quando explicita que a ideologia do ter representa "uma das bases fundamentais de toda alienação humana", e jamais será derrotada "se não for extinta a subalternidade sexual da mulher" (p. 57).

Reconhece Lukács, outrossim, que a situação da alienação entre indivíduos articula-se a uma crise cada vez mais extensa, expressa, sobretudo, nas condições da sociabilidade de classes atualmente em pauta, onde prevalece, como bandeira de luta, a autonomia econômica, como horizonte dos movimentos em favor da emancipação da mulher. Sem, por qualquer hipótese, desprezarmos a conquista da autonomia econômica, no aqui e agora da prática histórico-social, não podemos deixar de concordar com Lukács, que referida autonomia, além de necessariamente conturbada em todas as suas dimensões, vem, na verdade, contribuindo de forma relativamente inexpressiva para a emancipação feminina, não se tendo conquistado a igualdade efetiva entre homens e mulheres, quer no mercado de trabaIho, quer no âmbito da vida familiar.

A subalternidade sexual da mulher é a sua subalternidade em geral, logo, no limite, a luta contra a alienação sexual deve ser uma só com a luta pela emancipação humana. E ainda: a contraposição às diversas formas de alienação coincidirá com a luta pela construção de uma sociabilidade fundada em direção à própria autolibertação interior do indivíduo.

Na explicitação precisa de Lukács (1981),

Não é possível que a libertação (Befreiung) sexual isolada leve à verdadeira solução, o problema central, aquele de tornar humanas as relações entre os sexos. Sobretudo existe o perigo do quanto o desenvolvimento fez até hoje para tornar socialmente humana a pura sexualidade humana (erotismo) seja de novo perdido. Só quando os seres humanos tiverem encontrado relações recíprocas que os unifiquem como entes naturais (tornados sociais) e inseparavelmente como personalidades sociais, será possível superar verdadeiramente a alienação na vida sexual (p. 42).

A rigor, pelo desrespeito às relações humanas mediadas pela categoria do ter, é que presenciamos aberrações nas personalidades dos indivíduos. Assim, o masoquismo, a subjugação absoluta da mulher à excentricidade pornográfica são valores apregoados e naturalizados num estágio cada vez mais deprimente da degenerescência humana provocada pela reprodução das relações alienadas. Tais práticas são manifestações assentes ao capitalismo, objetivadas através de mecanismos ideológicos para subjugar a mulher à condição de mercadoria. Este fato não deixa dúvidas de que o puro ingresso das mulheres no mercado de trabalho não pode representar a plena emancipação do gênero feminino.

Nessa direção, é de fácil constatação que, em última análise, a mulher continua premida a cumprir os afazeres domésticos, assumindo uma tríplice jornada de trabalho; oprimida e ridicularizada como mercadoria pela sociedade capitalista; vítima da moralidade burguesa preconceituosa, limitada à estipulação de um padrão de comportamento feminino subjugado à perpetuação do machismo; aviltada frente à desigualdade de oportunidades no mercado de trabalho; dentre outras práticas que demonstram, a um só tempo, a falsa emancipação feminina e a perpetuação da alienação da sexualidade.

Fortalecemos nossa análise, apelando, mais uma vez, à Holanda (2005, p. 57), que assim interpreta a posição do filósofo magiar:

Para Lukács, a efetiva igualdade das mulheres no trabalho e na família deve ser conquistada a partir do terreno específico no qual tem sido bloqueada, o da própria sexualidade. Isto implica não apenas lutar contra os impulsos alienantes derivados do homem, mas deve igualmente apontar em direção à própria autolibertação interior. 
Somente com a instauração do comunismo, conforme Lukács (1981), a dimensão sensível dos indivíduos poderá beneficiar-se plenamente do desenvolvimento econômico e espiritual historicamente produzido pela humanidade. O mesmo autor assevera, com muita justeza, ter Marx reconhecido o caráter contraditório da história e, ainda que não tenha determinado as características da sociabilidade comunista, apontou as mudanças necessárias na essência das subjetividades dos indivíduos em direção à superação da categoria do ter vinculada à propriedade privada sobre a qual se reproduz a sociedade de classes.

Com efeito, corroborando com Marx, Lukács (1981) recupera que o percurso histórico realizado pela humanidade desde o escravismo até o sistema capitalista é permeado pela lógica da reprodução social fundamentada nas relações alienadas. Isto significa, como apontado anteriormente, que o processo de objetivação/exteriorização do homem é refletido de forma alheia ao próprio objeto produzido; ao processo de sua produção; ao seu gênero; aos outros homens e a si mesmo. Sua própria objetivação retorna em forma de exteriorização alienada impossibilitando o desenvolvimento da personalidade do indivíduo, que, então, permanece aprisionado ao seu mero particularismo, obstando a elevação do gênero em-si em direção ao gênero para-si. O capitalismo agrava esse processo, considerando que, pela primeira vez na história, todos os indivíduos são concebidos como dotados de liberdade para mudar de posição social.

Nesse escopo, as determinações individuais e sociais das diversas formas de alienação no campo das relações entre homens e mulheres, exploradores e explorados, alienadores e alienados, acompanharam o desenvolvimento econômico dos últimos séculos, considerando que a necessidade da reprodução do capitalismo aumentou a lucratividade dos empresários com a aquisição de mão-de-obra barata, o que abriu as portas para o ingresso das mulheres no mercado de trabalho. Diante desse quadro, como elucida Lukács (1981), foram lançadas as possibilidades da condução feminina a uma existência economicamente autônoma em relação aos homens.

Em verdade, não haveria como desconsiderar as muitas conquistas históricas alcançadas pelas mulheres com força, luta e derramamento de sangue. Tal formulação nos conduz a afirmar que a consciência do alienante e do alienado não se contrapõe à premissa do plano ontológico geral, quer dizer, até mesmo nesse contexto de alienação dos indivíduos, onde carecem de igualdade de oportunidades para se desenvolver, está posta a possibilidade de que estes venham a lutar contra a lógica da exploração do homem pelo homem e, outrossim, vislumbrar o desenvolvimento em busca de uma personalidade não-mais-particular.

Como nos ensina a ontologia marxiana, é da maior importância assinalar, que a história da humanidade não sofre a determinação absoluta de qualquer modo de produção econômico-social, muito ao contrário, o movimento da história, deve ser entendido como uma construção dinâmica, contraditória e dialética. Sob esta contingência, dá-se a possibilidade da superação da sociabilidade burguesa e a necessidade imprescindível da luta contra-sistêmica, no horizonte da emancipação da humanidade. Nessa perspectiva, a batalha pela efetivação da emancipação feminina deve estar atrelada à luta contra as diversas formas de exploração do homem pelo homem.

\section{Alienação da sexualidade e questão de gênero no contexto contemporâneo: a Declaração de Pequim em foco}

Delineados seus fundamentos ontológicos mais gerais, podemos trazer a problemática da alienação sexual para o contexto da sociabilidade capitalista contemporânea.

Assentada, sobre as prerrogativas do trabalho alienado, em sua forma assalariada, a qual permite a extração da mais valia e a consequente acumulação do lucro, a sociedade capitalista hodierna, como explica Mészáros (2003), estaria marcada por uma crise de caráter estrutural do próprio capital, de profundidade inédita na história desse modo de produção, com implicações severas sobre todas as dimensões da vida humana.

Conforme o mesmo autor, diante do agravamento dos processos de destruição produtiva e produção destrutiva postos em ação a serviço da reprodução do lucro e a consequente intensificação da barbárie social, as relações entre os indivíduos, são particularmente fetichizadas e 
reificadas, conquanto agudiza-se o processo de mistificação dos determinantes do real, historicamente requerido por um sistema que se edifica através da exploração do homem pelo homem.

Nesse quadro, os organismos internacionais de defesa dos interesses do capital criam ou recriam mecanismos diversos sob a pretensão de humanizar algo, cuja desumanidade é inerente à sua própria lógica, ou seja, à lógica expansiva, destrutiva e abrangente da reprodução social do capital. Ombreando-se com o capital, no intuito de gerir a crise, garantindo a passivização das massas, produz eventos grandiosos, dos quais, via de regra, resultam grandiloqüentes declarações, que, invariavelmente, apelam ao consenso e, de um modo geral, à esfera da pura subjetividade, para a amenização das sempre mais profundas tragédias sociais, desde o alívio da pobreza extrema à equalização das relações de gênero.

É nessa linha de raciocínio que podemos situar a paradigmática Declaração de Pequim, a qual coroou a IV Conferência Mundial sobre as Mulheres. mediante a participação de aproximadamente 180 países, cujos signatários aprovaram um elenco expressivo de medidas sensíveis à igualdade de direitos das mulheres em relação aos homens. Referido evento foi considerado pela Organização das Nações Unidas, um fórum de extrema relevância para o debate acerca da questão do gênero, sendo oportuno ressaltar que os organismos internacionais capitaneados pela ONU e pelo Banco Mundial tratam os Direitos da Mulher como um conjunto de princípios arrolados em Conferências, Convenções e Declarações, a exemplo daquelas vinculadas ao Projeto de Educação para Todos. ${ }^{3}$

Como registra Guarnieri (2010), a esse respeito:

Por meio da Declaração [de Beijing], os países reafirmam o compromisso com a igualdade de direitos e com os demais propósitos e princípios consagrados na Carta das Nações

\footnotetext{
${ }^{3}$ Para uma análise devidamente abrangente do conjunto de documentos produzidos no bojo desse Projeto, desde a Primeira Conferência Mundial de Educação para Todos (Jomtien, 1990), vale conferir os resultados da pesquisa O Movimento de Educação para Todos e a crítica marxista, parcialmente registrados em Jimenez e Mendes Segundo (2007); e Rabelo, Mendes Segundo e Jimenez (2009), dentre outros.
}

Unidas, na Declaração Universal dos Direitos Humanos e em outros instrumentos internacionais de direitos humanos, como a Convenção sobre a Eliminação de Todas as Formas de Discriminação contra a Mulher, a Convenção sobre os Direitos da Criança, a Declaração sobre a Eliminação da Violência contra a Mulher e a Declaração sobre o Direito ao Desenvolvimento [...] (p. 24).

De toda sorte, como não poderia ser de outra forma diante das presentes condições da luta de classes, não obstante a hipotética boa vontade de seus formuladores, o teor das programáticas e recomendações produzidas nesse espaço, guardando um mistificador distanciamento em relação às determinações essenciais da opressão de gênero, acaba por traduzir primordialmente um rol de intenções fadadas a confinar-se ao plano da retórica.

Este parece ser o caso dos termos da Declaração de Pequim, aqui enfocada.

A Declaração de Pequim enunciada por ocasião do aniversário de número cinquenta das Nações Unidas, em 1995, foi adotada, como dito acima, pela IV Conferência Mundial sobre as Mulheres, tendo como principais requisitos norteadores: Ação para igualdade; e Desenvolvimento e paz, com destaque inconfundível à inclusão das mulheres no mercado de trabalho.

O objetivo da referida Conferência expressa a pretendida abrangência, sendo definido no item 10 da Declaração de Pequim (1995):

Impulsionar o consenso e o progresso alcançados nas anteriores Conferências das Nações Unidas - sobre as Mulheres em Nairóbi em 1985, sobre as Crianças em Nova York em 1990, sobre o Meio Ambiente e o Desenvolvimento no Rio de Janeiro em 1992, sobre Direitos Humanos em Viena em 1993, sobre População e Desenvolvimento no Cairo em 1994 e sobre Desenvolvimento Social em Copenhagem em 1995, com os objetivos de atingir a igualdade, o desenvolvimento e a paz (p. 04).

Os governos participantes dessa Conferência assumiram a responsabilidade de efetivar uma Plataforma de Ação que pudesse garantir uma perspectiva de gênero voltada para políticas e programas de cada país, como podemos observar no item 38: 
Pela presente nos comprometemos, na qualidade de Governos, a implementar a seguinte Plataforma de Ação, de modo a garantir que uma perspectiva de gênero esteja presente em todas as nossas políticas e programas. Nós insistimos ao sistema das Nações Unidas, às instituições financeiras regionais e internacionais e às demais relevantes instituições regionais e internacionais e a todas as mulheres e homens, como também às organizações não governamentais, com pleno respeito à sua autonomia, e a todos os setores da sociedade civil que, em cooperação com os Governos, se comprometam plenamente e contribuam para a implementação desta Plataforma de Ação (DECLARAÇÃO DE PEQUIM, 1995, p. 04).

Outras diferentes passagens da Declaração, como as que arrolamos abaixo, servem de ilustração suficiente de uma abordagem que, deslocada das premissas colocadas pela ontologia marxiana, pretende situar a emancipação da mulher nos marcos do sistema do capital, sem o devido aceno à necessidade da superação da alienação, que, desde sua gênese no trabalho explorado, atravessa todos os complexos da sociabilidade, atingindo frontalmente, como vimos tentando demonstrar, as relações entre os gêneros e, por extensão, a condição da mulher.

Assim, o item 12 da Declaração de Pequim (1995, p. 02) atesta a necessidade de se possibilitar a realização do pleno potencial das mulheres, estabelecendo:

O fortalecimento e o avanço das mulheres, incluindo o direito à liberdade de pensamento, consciência, religião e crença, o que contribui para a satisfação das necessidades morais, éticas, espirituais e intelectuais de mulheres e homens, individualmente ou em comunidade, de forma a garantir-Ihes a possibilidade de realizar seu pleno potencial na sociedade e organizar suas vidas de acordo com as suas próprias aspirações.

Situado no cenário do discurso democrático da igualdade, o Artigo 15 da mesma Declaração (1995, p. 02) associa a igualdade de direitos entre homens e mulheres à condição de efetivação do bem estar familiar e da democracia:

A igualdade de direitos, oportunidades e acesso aos recursos, a distribuição equitativa das responsabilidades familiares entre homens e mulheres e a harmônica associação entre eles são fundamentais para seu próprio bem-estar e de suas famílias, como também para a consolidação da democracia.

Mais uma vez descolada da análise que busca a essência do movimento do real, para além de sua aparência fenomênica, a Declaração de Pequim aposta no desenvolvimento sustentado como estratégia de erradicação da pobreza, propalando a participação conjunta e equânime de mulheres e homens nesse processo.

Assim, reza o Item 16 que,

A erradicação da pobreza baseada no crescimento econômico sustentado, no desenvolvimento social, na proteção do meio ambiente e na justiça social, requer a participação das mulheres no desenvolvimento econômico e social, a igualdade de oportunidades e a plena e equânime participação de mulheres e homens como agentes beneficiários de um desenvolvimento sustentado centrado na pessoa (DECLARAÇÃO DE PEQUIM, 1995, p. 02).

No Item 24, a Declaração (1995, p. 03) assevera ainda: "estamos determinados a [...] Adotar todas as medidas necessárias para eliminar todas as formas de discriminação contra mulheres e meninas e remover todos os obstáculos à igualdade de gênero e aos avanços e fortalecimento das mulheres".

Mais adiante, os signatários da Declaração de Pequim (Item 26, p. 03) assumem o compromisso inequívoco de:

Promover a independência econômica das mulheres, incluindo o emprego, e erradicar a persistente e crescente pobreza que recai sobre as mulheres, combatendo as causas estruturais da pobreza através de transformações nas estruturas econômicas, assegurando acesso igualitário a todas as mulheres, incluindo as mulheres da área rural, como agentes vitais do desenvolvimento, dos recursos produtivos, oportunidades e dos serviços públicos.

A Declaração de Pequim (item 30, p. 04,) almeja também "Assegurar a igualdade de acesso e a igualdade de tratamento de mulheres e homens na educação e saúde e promover a saúde sexual e reprodutiva das mulheres e sua educação." 
Em tom análogo, o Item 35 não se omitiu em focalizar mais uma vez a questão econômica, agora acoplada ao acesso aos meios de desenvolvimento científico e profissional, dentre outros fatores, como uma solução para a problemática das desigualdades entre os indivíduos, sobretudo, no que toca à questão do gênero. Por conseguinte, promulga:

Assegurar às mulheres a igualdade de acesso aos recursos econômicos, incluindo a terra, o crédito, a ciência, a tecnologia, a capacitação profissional, a informação, a comunicação e os mercados, como meio de promover o avanço e o fortalecimento das mulheres e meninas, inclusive através da promoção de sua capacidade de exercer os benefícios do acesso igualitário a estes recursos, para o que se recorre, dentre outras coisas, à cooperação internacional (DECLARAÇÃO DE PEQUIM, 1995, p. 04).

Vale esclarecer que, no âmbito de nossa crítica referenciada no marxismo e, mais particularmente, na contribuição de Lukács, a partir de Marx, acerca da alienação da sexualidade e da opressão feminina, não se trata de condenar sem mais, o conteúdo da Declaração de Pequim, ou de nos posicionarmos contrariamente e de forma arbitrária, aos diversos pontos do documento. Não nos ocorre, por exemplo, desmerecer a necessidade de se oferecer as melhores oportunidades quanto ao cuidado da saúde da mulher (Item 30 da Declaração); negar a que seja assegurada à mulher a liberdade de pensamento e de ação sobre sua própria vida (Item 12); assim como admitimos a importância, absolutamente óbvia, da distribuição equitativa das responsabilidades domésticas entre homens e mulheres (Item 15); ou do mais pleno acesso da mulher aos campos da educação, da ciência e da tecnologia (Item 35).

Por outro lado, como nos ensinam Marx, Lukács e seus intérpretes autênticos, não podemos presenciar uma forma de igualdade genuína nas relações entre os indivíduos, numa sociabilidade de classes fundada pela lógica do ter em detrimento do ser. Contrariamente à análise marxista da realidade social e histórica, a Declaração de Pequim (1995, p.03) acaba por postular ser possível ao capitalismo, dar cabo da discriminação contra as mulheres, além de exterminar a pobreza e promover o desenvolvi- mento sustentável e garantir a paz no mundo, vale ressaltarmos.

O que devemos ter em conta é que, não obstante o tom de um modo geral progressista que marca a referida Declaração, admitindo pontualmente, a necessidade de "combate às causas estruturais da pobreza através de transformações nas estruturas econômicas" (1995, p. 03), o documento não avança ao ponto de assumir a superação do trabalho explorado, alienado, e, por conseguinte, do próprio sistema do capital, como condição de emancipação das mulheres e dos homens, comprazendo, nesse horizonte, a liberdade de todos os indivíduos de dirigir sua vida, para além do acinte da mercadoria.

Compreendemos, em outras palavras, que a igualdade de oportunidades para que os indivíduos possam, efetivamente, se desenvolver em busca de uma personalidade não-mais-particular não tem como realizar-se por meio de medidas que não visem à reestruturação radical das bases econômico-sociais vigentes, entendendo, com Tonet (2005), na esteira de Marx, que qualquer forma de humanização do capital está fadada ao fracasso.

É patente que, em pleno século XXI, a opressão da mulher ainda não foi - como não poderia ter sido - superada, o que caracteriza a alienação de ambos os sexos. Ao contrário, no quadro da crise estrutural, os processos de violação à dignidade humana vêm sendo flagrantemente potencializados. Nesse contexto, os efeitos da Conferência de Pequim, ao que se pode comprovar, datados mais de 15 anos de sua realização, ainda estão por se evidenciar, com alguma expressividade ${ }^{4}$.

\section{Considerações finais}

No presente artigo, explicitamos algumas nocões acerca do trabalho alienado como um

\footnotetext{
${ }^{4}$ É oportuno assinalar, a esse respeito, que, por ocasião da 54a. Sessão da Comissão das Nações Unidas sobre o Estatuto da Mulher, um evento realizado em 2010 e que veio a denominar-se Pequim +15 , procedeu-se a uma revisão quanto ao alcance das metas estipuladas em 1995, chegando-se à conclusão de que "não obstante os progressos obtidos na realização dos objetivos estratégicos da Plataforma de Acção de Pequim, persistem as desigualdades e estereótipos de género, continuando as mulheres a ocupar uma posição subalterna relativa aos homens nos domínios visados na Plataforma" (Jornal Oficial da União Europeia, 25/02/2010).
} 
complexo social e historicamente construído como uma necessidade da reprodução da sociabilidade de classes, considerando que, como assevera Mészáros (2009), com base em Marx e Lukács: a transcendência positiva da alienação significa a própria superação da sociabilidade fundada na subsunção do trabalho ao capital.

Sobre esta base, tentamos avançar sobre a problemática da alienação da sexualidade, a partir de Lukács após Marx, atestando, ao fim e ao cabo, que a luta pela emancipação feminina deverá articular-se à luta pela própria emancipação humana.

Elementos introdutórios foram apontados, então, em relação à chamada Declaração de Pequim como uma ilustração da retórica dominante que enuncia a problemática afeta à alienação da sexualidade no contexto do capitalismo contemporâneo. Com base em nossa perspectiva de análise, não pudemos deixar de situar a referida Declaração no campo da reprodução do status quo. Mesmo admitindo a hipótese de que seus signatários deixaram-se guiar pelas mais retas intenções, certamente disputando o teor da Declaração, com porta-vozes marcadamente conservadores, devemos assinalar o caráter, em larga medida, parcial e mistificador das formulações ali contidas.

Com efeito, numa sociabilidade de conflitos cotidianos, as relações alienadas são manifestadas na vida dos indivíduos de acordo com os mecanismos do capitalismo que, no atual estágio da luta de classes, agravam crescentemente a exploração do homem pelo homem. No cenário da crise capitalista contemporânea, ainda mais, as possibilidades dadas aos indivíduos para seu pleno desenvolvimento restringem-se, crescentemente, à esfera do discurso e, ainda, às determinações promulgadas pelos organismos internacionais de defesa dos interesses do capital - Banco Mundial e instituições congêneres - no sentido de assegurar a reprodução do sistema frente à sua crise estrutural.

Não obstante o desenvolvimento contraditório entre individualidade e gênero humano com relação ao enriquecimento ou à degradação das personalidades dos indivíduos, devemos reconhecer que estes, mesmo na sociabilidade de classes - com todas as suas distorções - criaram a riqueza material e espiritual que contribui para a importantíssima construção do reino da neces- sidade. Este é a base material para lutarmos em direção à possibilidade da construção do reino da liberdade, como reafirma Lukács (1978).

Com relação à questão do gênero, conforme destacamos ao longo do texto, não é possível a superação efetiva da categoria do ter, sem que ocorra uma efetiva emancipação feminina como um meio - e não como fim - para a emancipação plena dos indivíduos em sua totalidade. Até porque, conforme destacado em nossa exposição, para Lukács (1981), por meio da relação entre homem e mulher é possível avaliarmos as diversas formas de relação entre os indivíduos, ou, nos termos colocados por Marx (2008), o nível de civilidade que uma dada forma de sociabilidade conseguiu atingir.

Como podemos atestar nos nossos cotidianos alienados, assim como reitera Lukács (1981), a história da alienação sexual é marcada pela imposição da disponibilidade sexual da mulher. Esta é tratada, via de regra, como um objeto de posse de um homem para posse de outro homem. Contudo, havemos que registrar a resistência heroica contra as diversas formas de opressão sofridas pelas mulheres ao longo da pré-história da humanidade - a reprodução social fundada na lógica da expropriação brutal da dignidade e da força de trabalho dos indivíduos - como coloca Lukács (1981). Diante de tais práticas, apontamos que a luta realizada pelas mulheres dentro da totalidade social é um fato presente ao longo da história dos indivíduos como manifestação de resistência frente ao processo de alienação.

Enquanto indivíduos alienados, por certo conservamos, no próprio processo de alienação, a generidade em-si, não podendo ser cancelada a consciência do ser em-si em busca da construção das possibilidades de transformação autentica do gênero humano, ou seja, de generidade em-si para o desenvolvimento da generidade para-si.

Finalizando nossa reflexão, reafirmamos, contrariando os postulados atrelados ao fim da história, que esta não acabou. Conquanto, podemos lutar contra a problemática da alienação sexual, entranhada ao trabalho alienado, fundamento onto-histórico das heterogêneas formas de alienação peculiares à sociabilidade de classes, sobretudo, porque vivemos em um processo contraditório e dialético movido por um 
complexo de complexos de múltiplas determinações. Por esse mesmo prisma, reafirmamos que a luta em prol da emancipação feminina não pode deixar de estar organicamente atrelada à superação do trabalho alienado e da propriedade privada, como condição precípua da emancipação humana.

\section{Referências}

GUARNIERI, T. H. Da criação da ONU (1945) à Conferência de Beijing (1995). Revista Eletrônica da Faculdade Metodista Granbery. N. 8, Jun. 2010, pp. 1-27. Recuperado de http://re.granbery.edu.br em 12 de junho de 2013.

HOLANDA, Maria N. Alienação e Ser Social: determinações objetivas e subjetivas. Tese de Doutorado. Universidade Federal do Rio de Janeiro, 2005.

JIMENEZ, S. e MENDES SEGUNDO. M. D. Erradicar a pobreza e reproduzir o capital: Notas críticas sobre as diretrizes para a educação do novo milênio. Cadernos de Educação. Pelotas, N. 28, p. 119-137, Jan-Jun. 2007.

JORNAL OFICAL DA UNIÃO EUROPEIA. Pequim + 15 - Plataforma de Acção das Nações Unidas para a Igualdade de Gêneros. 25/02/2010. Recuperado em 12 de junho de 2013, de eur-lex.europa.eu/ LexUriServ.do?uri=OJ=C:2010:348E:0011:0014:PT :PDF

LUKÁCS, G. As Bases Ontológicas do Pensamento e da Atividade do Homem. Revista Temas de Ciências Humanas. São Paulo: Livraria Editora Ciências Humanas, N. 4, p. 1 - 17, 1978.

LUKÁCS, G. Per una Ontologia dell'Essere Sociale, v. 1 e 2. Roma: Ed. Riuniti, 1981.

MARX, K. Manuscritos Econômico-Filosóficos. São Paulo: Boitempo, 2008.

MARX, K. O Capital: crítica da economia política. Livro Primeiro - Tomo I. São Paulo: Nova Cultural, 1985.

MÉSZÁROS, I. O Século XXI: socialismo ou barbárie? São Paulo: Boitempo, 2003.

MESZÁROS, I. A teoria da alienação em Marx. São Paulo: Boitempo, 2009.

NAÇÕES UNIDAS. Declaração de Pequim adotada pela Quarta Conferência Mundial sobre as Mulheres: Ação para Igualdade, Desenvolvimento e Paz 1995. Disponível em: www.dhnet.org.br/ direitos/sip/onu/.../pequim95.htm. Acesso em10 de jun. 2010.

RABELO, J.; MENDES SEGUNDO, M. D; JIMENEZ, S. Educação para todos e reprodução do capital. Trabalho Necessário. UFF. Ano 7, N. 9, pp. 1-20, 2009.

TERTULIAN, N. Uma apresentação à Ontologia do ser social, de Lukács. Crítica Marxista, São Paulo, N. 3, pp. 54-69,1996.

TONET, Ivo. Educação, Cidadania e Emancipação Humana. Rio Grande do Sul: Unijuí, 2005. 